\title{
LINGUISTIC METHODS FOR INVESTIGATING CONCEPTS IN USE
}

\author{
M.M. Kurbanova ${ }^{1}$ \\ ${ }^{1}$ Tashkent State Transport University \\ Teacher, Uzbekistan, Tashkent \\ E-mail: kmukhabat25@gmail.com \\ G.B. Ataeva ${ }^{2}$ \\ ${ }^{2}$ Tashkent State Transport University \\ Teacher, Uzbekistan, Tashkent \\ E-mail: ataeva_gulchehra@mail.ru
}

\begin{abstract}
Annotation. The article examines the linguistic research methods used in modern linguistics. New approaches and techniques are proposed: inverse methods, matrix approaches.

Key words: approach, method, business approach, methodology, reversible method, matrix ap.
\end{abstract}

\section{Introduction}

One of the constant problems in the field of linguistics is the improvement of the methods of linguistic research. Despite the fact that most textbooks on linguistics address this problem, the methodology of linguistic research has become an object of special attention relatively recently: only since the 1990s did the first textbooks on the methods of linguistic research begin to appear. As many researchers testify, one of the problems of linguistic methodology is the disorder of the basic concepts used. The encyclopedias note that linguistic methods do not represent a single set of principles and methods of research and description of linguistic entities. Rather, it is a "menu" of complementary and / or mutually exclusive methods, used in different combinations and in different proportions in private linguistics and in specific linguistic studies. Moreover, this set is not permanent. It is constantly being enriched, and the attitude towards certain methods is also changing: in different historical periods and in different scientific schools, the same method may be dominant in linguistic practice or, on the contrary, scientifically discredited. According to A.T. Khrolenko, "the presence of a significant number of research methods requires, firstly, clarification of the very concept of "method of linguistics", and, secondly, raises the question of their classification. Both of these questions are closely related to each other and have not yet been resolved by modern linguistics. It was noted that the term method is ambiguous: it denotes an aspect of the study, methodology, techniques, methods of description, etc. Naturally, with such an undifferentiated approach to the definition of methods, it is difficult to create any scientific classification of linguistic methods.

That is why even the best works on the methodology of linguistics are limited to the description of more or less indisputable methods and place them in one row without indicating a classification hierarchy. It seems that any attempt to clarify the term method and present a consistent classification is useful for linguistics, since in the empirical sciences, which includes the science of language, classification is a way to gain new knowledge about the relationship of the studied phenomena and objects. The effectiveness of research is largely determined by the degree of development of research methods. Questions about how to study the linguistic material, where to start research, what stages of analysis need to go through, how much material is needed, what aspects, properties and characteristics of the object need to be analyzed and others arise for each scientist already at the first approach to the object. Therefore, the methodology of linguistic research is a traditional branch of linguistics and is represented in almost all textbooks known to us on introduction to linguistics and general linguistics. It can be especially difficult for novice researchers to understand the methodology of science due to the abundance of terms, the variety of their interpretations, modifications and classification principles. As a result, it is the methodology and methods that are defined in the works least competently.

\section{Main part}

Scientific literature on the methodology of linguistics is both a lot and a little. Currently, linguistics uses a number of terms to name research procedures - methodology, method, method, technique, approach, aspect, procedure, operation. Moreover, in many cases they are used in the same meaning, which makes it difficult for specialists to understand each other and presents a terminological problem. As we noted, “... the presence of several synonymous terms causes the specialists who use them to strive (explainable by the habit that different words have different meanings) to find a difference between them (often insignificant), which leads to distortion of their content. At the same time, the use of different terms causes uncertainty that the specialists who use them speak about the same concept. This leads to difficulties in mutual understanding and causes countless disputes about the terms. So, for example, the meanings diverged: former synonyms - instrument and document, atom and molecule, harbor and port, metal, mineral and ore; former options - crystal and crystallin, asbestos and lime, step and degree. The material borrowing of the viaduct and its literal translation of the viaduct diverged in semantics; material borrowing of the aqueduct and its two structural traces - a water conduit (water 
supply structure) and a water supply system (a complex of water supply facilities). It should be noted that each such discrepancy testifies to the next step in the development of our knowledge, when a vague idea is replaced by a more precise system of concepts that require new names. Such a situation, requiring the ordering of the simultaneously existing synonymy and polysemy of a number of terms, has developed at the present time in linguistics. Consequently, one of the first and long overdue problems of linguistic methodology is the classification and definition of basic concepts and clarification of the terms used.

Each of the methods has its own main research task, its own area of the object studied by science, its own range of basic requirements imposed on the researcher by the method. The method requires the researcher to subordinate the entire complex process of collecting classification and explaining facts to the main scientific task. Each special research method is embodied in the practice of scientific work in a certain system of logical actions and in a certain system of repetitive, more or less standardized methods of collecting, processing and generalizing facts. Such a system of techniques is also often called a method, but it is more convenient to call it a technique. The research method determines the way of cognition and interpretation of facts, and the methodology groups the facts themselves, classifies, shows them from the right side, puts them in different positions. V.I. Kodukhov distinguishes and describes in detail the following "basic methods of linguistic analysis": descriptive, comparative historical, comparative, stylistic, dialectographic, experimental phonetic and mathematica. Later, he names two methods of linguistic research as the main ones - descriptive and comparative; within the framework of the comparative method, he distinguishes, in turn, comparative-historical, historicalcomparative (traditionally called historical) and comparative [3, p. 224 et seq.]. 280 V.N. Yu.S. Nemchenko Stepanov considers the following methods as "the main special methods of linguistics": algebraic (or set-theoretic), functional, opposing, distributive, representative and some others [1, p. 59 et seq.]. I.P. Raspopov, describing the methods of synchronous analysis of the language, distinguishes among them the following: the method of distributive analysis, the method of differential analysis and the transformational method. I.V. Arnold emphasizes (along with others) and examines in detail such "methods and procedures of linguistic analysis": hypothetical-deductive method, opposition method, distributive analysis, distributive-statistical analysis, component analysis. As an independent research method, he singles out "the method of automatic text analysis using computers". As can be seen from all that has been said above, in modern linguistics there is no sufficiently clear understanding of the concept of the method of scientific research, there is no complete clarity in the issue of distinguishing between research methods and other related phenomena.

The main linguistic methods of assimilation (analysis) of facts are: descriptive, comparative and normative-stylistic.

Descriptive is a method of synchronous analysis of one language. The material is considered outside of its assessment from the point of view of the norm.

Normative-stylistic - the establishment of existing norms on the basis of a descriptive method and the development of recommendations of a normative-stylistic nature based on certain criteria.

The comparative historical method is the first scientific method in linguistics (formed in the first half of the 19th century). Its purpose is to explain the origin of genetically related languages from a common source. Reconstruction of certain proto-forms is a deductive study based on certain scientific premises.

Private methods of a descriptive approach to language:

Techniques (private methods) for the descriptive study of phenomena: distributive analysis, differential analysis, transformational method, etc.

Distributional Analysis Method (DA)

The goal is to give a classification of linguistic units of a particular level according to their syntagmatic properties (according to their distribution in the flow of speech). To do this, you need to find out in what contexts this linguistic unit appears, in what environment it can be in the process of functioning.

The use of different methods of describing one material allows you to deeper knowledge of linguistic reality.

The application of distributive analysis in morphology is complicated by the fact that the number of elements is greater than in phonology. Similar classifications also exist in traditional linguistics. By what principle are nouns distributed according to declensions? The 3 types of declensions are nothing more than the distribution of nominal (substantive) stems relative to inflections. These are the distribution classes.

In word formation, it is also possible to use the method of distributive analysis. The combinatory potential of different stems with affixes allows us to distinguish into different classes.

Another very promising method emerged in the late 20th century in comparative linguistics: the reverse method. This research method is used to study the semantic aspects of the systemic comparison of vocabulary, taking into account hyponymic, synonymous and polysemic relations. This is especially important in the field of special vocabulary, since the study of these particular aspects makes it possible to reveal the current state of national terminologies, not limited to comparing their formal characteristics, and to determine the possibility of establishing equivalence relations between them. It is convenient to conduct such research on the material of bilingual dictionaries, which contain a lot of information about the semantic relations of lexical systems of different languages. This research is carried out by comparing information from dictionaries of the same volume, but of different directions, for example, English-Russian and Russian-English. In some cases, such dictionaries exist, compiled by the same authors, which simplifies comparison. We believe that such a 
study will make it possible to formulate well-thought-out and scientifically grounded recommendations for streamlining national terminologies and establishing equivalence between their terms. In addition, it makes it possible to obtain very important results for a number of areas of terminology, lexicographic, informational and cognitive works, among which, first of all, it should be mentioned: - identification of systems of semantic (polysemic, synonymous, hyponymic) relations of terms that determine the specifics of national terminologies; - determination of existing opportunities to increase the reversibility (that is, one-to-one correspondence) of translation of terms in dictionaries and text, which can significantly improve the quality of scientific and technical translation; - identification of the most typical mistakes made by the authors of modern translation dictionaries; - creation of additional prerequisites for the industrial implementation of machine translation systems; - identification of national characteristics Bulletin of vocabulary perception, which contributes to the study of the characteristics of national psychology and the development of knowledge in the field of scientific cognition and their modeling in artificial intelligence systems. Examples of the application of this proposed by us method are described in a number of articles [Grinev 1997, Grinev 1999]. The reverse method is often used in modern scientific research: in a number of dissertation works [Mironova 2001; Fadeeva 2005; Pankratova 2005; Ushkova 2007; Tarasova (Dunina) 2009]. This method is used to highlight lexical-semantic groups and to analyze the meaning of a word [Konovalova 1988; Sternin 1988]. The analysis of such phenomena as polysemy and synonymy is based on the principles of reflecting the semantic structure of the translated word existing in lexicography: individual meanings of the word are marked with Arabic numerals (homonyms are given in separate articles and marked with Roman numerals), the shades of meaning are separated by a semicolon, synonym translations are separated by commas. Thus, the dictionary clearly presents information about polysemy and homonymy, as well as synonymy - full and partial (quasi-synonymy, conditional synonymy that exists between translations of shades of meaning). The principle of operation of the reverse method can be illustrated by the following example. When analyzing the Russian-English and English-Russian correspondences in the dictionaries of O.S. Akhmanova and ABBYY Lingvo, we find that the word "sofa" is given three translation options: sofa; - (with pillows and cushions) ottoman; - (seat only) settee. The first of them, in turn, is given two translation options: "sofa" and "sofa". The second - three options: "ottoman", "ottoman" and "sofa". To the third, there is only one option: a return to the term "sofa". The second turn of the translation - the search for English equivalents to the identified new Russian terms - gives a translation for the word "sofa" - sofa, and for the words "ottoman" and "ottoman" the same single translation - ottoman. Thus, in fact, when translating, two groups of words (semantic microfields) are compared - in Russian the words "sofa", "sofa", "ottoman" and "ottoman", and in English - sofa, ottoman and settee. Studies have shown that the reverse method allows you to find out how much the semantic volume of the meaning of lexemes, represented by dictionaries as equivalents, differs. Consequently, this method makes it possible to clarify the semantic scope of the concept indicated by the analyzed term in a particular language. The emergence of writing creates the possibility of implementing another new method that we have developed - the method of reconstructing the mentality of an early person and studying its development on the basis of the vocabulary he uses. For this, it is necessary to move from the description of the historical development of semantic fields (lexical groups, lexical-semantic groups) to understanding and interpreting changes in the process of such development.

\section{Conclusion}

In conclusion we can define methods in accordance with the purpose, objectives and material of the study used in the work are:

- morphemic analysis of derivatives, in particular, analysis by NS;

- analysis and comparison of dictionary definitions;

- semantic analysis of the derivative the words..;

- contextual analysis;

- quantitative comparisons;

- analysis of the grammatical (word-formation) linguistic subsystem as a field-type continuum ...

"The main methods for solving the assigned tasks were:

- the method of linguistic observation anddescriptions;

- method of generalization and comparison;

- sociolinguistic analysis based on

method of correlation of linguistic and social phenomena;

- the method of contextual and linguistic analysis

- the method of reverse" 


\section{References:}

\# Stepanov Yu.S. Methods and principles of modern linguistics. 2nd ed. M .: Editorial URSS,2001.312 s.

\# Golovin B.N. Introduction to linguistics. 4thed. M .: Higher school, 1983.232 p.

* Kodukhov V.I. General linguistics. Moscow: Higher school, 1974.304 p.

* Arnold I.V. Fundamentals of Scientific Researchin linguistics. M .: Higher school, 1991.139 p.

* General linguistics. Linguistic research methods. Moscow: Nauka, 1973.318 p. Great Soviet Encyclopedia. 3rd ed. /

* Ch. ed. A.M. Prokhorov. Moscow: Soviet Encyclopedia, 1974.T. 16.615 p.

* Big encyclopedic dictionary / Ch.ed. A.M. Prokhorov. M .: Soviet encyclopedia, 1991. T. 1. 862 s. Small Soviet Encyclopedia. 3rd ed. / Ch. ed. B.A. Vvedensky. Moscow: Great Soviet Encyclopedia, 1959.Vol. 5.1309 p.

* Philosophical Encyclopedic Dictionary /Ch. ed. L.F. Ilyichev. M .: Soviet encyclopedia,1983.839 s.

\# Akhmanova O.S. Linguistic Dictionaryterms. M .: Soviet encyclopedia, 1966. 608 p.

\# Kodukhov V.I. Methods of linguistic analysis: Lectures on the course "Introduction to Linguistics".L .. Leningrad State. ped. Institute, 1963.128 p.

\# Raspopov I.P. Methodology and technique of linguistic research. Synchronous methodslanguage learning: manual for a special course. Voronezh:Voronezh University Publishing House, 1976.110 p.

* Kade T.Kh. Scientific methods of linguisticResearch: Study Guide. Krasnodar: Publishing houseKuban state unta, 1998.139 p.

* Ogrokhina E.A. The expression of negation in modern German word formation: derivatives withmorpheme un-: Author's abstract. dis ... cand. philol. Sciences:10.02.04. SPb., 1997.18 p.

* Vasiltsova N.V. Unintentional and intentional abnormalities in the language of the media:Author's abstract. dis ... cand. philol. Sciences: 10.02.01. - Rostov on / D., 2004.27 p.

\# Korshunova L.S. Lexico-semantic groups of verbs of speaking, mental activity, feelings in the dialects of the Nizhny Novgorod region:Author's abstract. dis ... cand. philol. Sciences: 10.02.01. Lower Novgorod, $2002.19 \mathrm{~s}$ 